\title{
ARTICLE
}

\section{Homogeneous Cobalt-Catalyzed Deoxygenative Hydrogenation of Amides to Amines}

Received 00th January 20xx, Accepted 00th January 20xx DOI: $10.1039 / \times 0 \times x 00000 x$

\author{
Veronica Papa, ${ }^{a}$ Jose R. Cabrero-Antonino*a,b Anke Spannenberg, ${ }^{a}$ Kathrin Junge ${ }^{a}$ and Matthias \\ Beller*a
}

\begin{abstract}
The first general and efficient cobalt-catalyzed deoxygenative hydrogenation of amides to amines is presented. The optimal catalytic system based on a combination of $\left[\mathrm{Co}\left(\mathrm{NTf}_{2}\right)_{2}\right]$ and ( $p$-methoxy)triphos (L3) in the presence of [Me 3 SiOTf] as acidic co-catalyst facilitates the direct hydrogenation of a broad range of amides to the corresponding amines under mild conditions. A set of control experiments indicate that, after the initial reduction of the amide carboxylic group to the wellknown hemiaminal intermediate, the reaction mainly proceeds through $\mathrm{C}-\mathrm{O}$ bond cleavage though other pathways might be also involved to a minor extent.
\end{abstract}

\section{Introduction}

Amines are abundantly common in agrochemicals, pharmaceuticals, and natural products. ${ }^{1}$ While aliphatic amines are generally obtained industrially on a large scale via reductive aminations, ${ }^{1 \mathrm{~d}}, 1 \mathrm{e}, 1 \mathrm{~g}, 2$ primary aromatic and benzylic amines are produced by nitroarene ${ }^{3}$ and/or nitrile 4 group reductions. In addition, reductive $\mathrm{N}$-alkylations using readily available and stable carboxylic acid derivatives were developed in recent years. ${ }^{5}$ In principle, the direct hydrogenation of carboxylic acid amides is highly attractive for the synthesis of a broad variety of amines. ${ }^{6}$ For instance, ammonia, as well as primary and secondary amines can be easily transformed to the corresponding amides. ${ }^{7}$ With subsequent hydrogenation, primary, secondary or tertiary amines with increased molecular complexity may be afforded. ${ }^{6}$ However, performing such reactions under mild conditions remains highly challenging. ${ }^{6 e, 6 \mathrm{~g}}$ Compared to well-known stoichiometric reductions of amides, 1d, 1g, 8, 9 the straightforward catalytic hydrogenation of such substrates is intrinsically greener as only water is formed as a co-product. ${ }^{6}$ However, owing to the thermodynamic and kinetic stability of amides, such hydrogenations represent a very difficult task. ${ }^{6 e}$, $6 \mathrm{~g}$ More recently, catalytic protocols employing silanes or boranes have been developed showing excellent functional group tolerance.6a-c, 10 Yet, all these methodologies suffer from the generation of large amounts of waste-products and often require complex and hazardous work-up procedures. To overcome these drawbacks, the use of

\footnotetext{
a. Leibniz-Institut für Katalyse e.V. Albert-Einstein Str. 29a, 18059 Rostock (Germany) Email: matthias.beller@catalysis.de

b. Instituto de Tecnología Química. Universitat Politécnica de València-Consejo Superior Investigaciones Cientificas (UPV-CSIC). Avda. de los Naranjos s/n, 46022 Valencia (Spain).E-mail: jcabrero@itq.upv.es

Electronic Supplementary Information (ESI) available: [Detailed experimental procedures, additional tables, schemes, figures, products characterization data and NMR spectra of all the isolated products.]. See DOI: 10.1039/x0xx00000x
}

molecular hydrogen is highly desired. ${ }^{6}$ Unfortunately, given the low electrophilicity of the carbonyl amide group and complex selectivity issues, its environmental-friendly hydrogenation continues to be problematic. ${ }^{6 e}, 6 \mathrm{~g}$

In general, amide hydrogenations ${ }^{6 e}$ can occur via two different pathways (C-O or $\mathrm{C}-\mathrm{N}$ bond cleavage $)^{11}$ after the initial hemiaminal formation (tetrahedral intermediate) ${ }^{12}$ (Scheme 1 ). While the $\mathrm{C}-\mathrm{O}$ cleavage (deoxygenative hydrogenation) gives the $\mathrm{N}$-alkylated amine and $\mathrm{H}_{2} \mathrm{O}$ (Scheme 1 , path A), the $\mathrm{C}-\mathrm{N}$ cleavage (deaminative hydrogenation) produces the original amine and the corresponding alcohol, or the aminoalcohol (Scheme 1, path B). From a synthetic and practical point of view, the synthesis of the higher amine by the deoxygenative hydrogenation is the more desired transformation (Scheme 1, path A). ${ }^{8 b}$ Indeed, this process is considered as one of the three most desirable transformations for future development by the ACS Green Chemistry Institute and members of the Pharmaceutical Roundtable. ${ }^{13}$

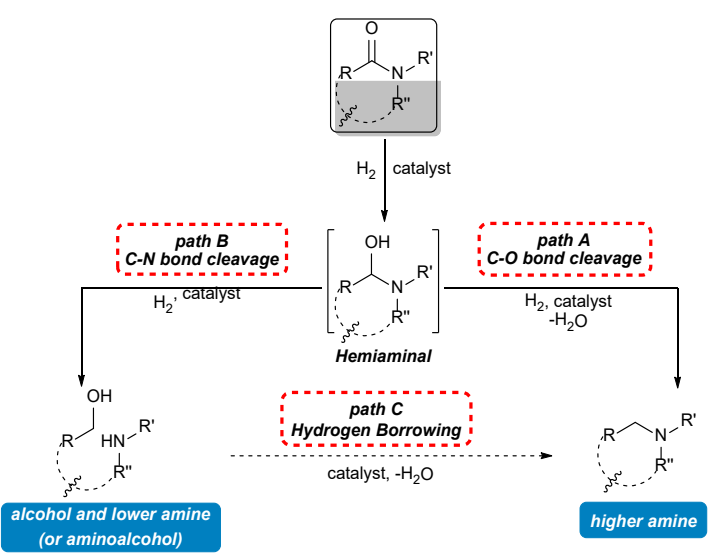

Scheme 1 Hydrogenation of amides: possible reaction pathways.

Applying heterogeneous catalysts for amide hydrogenation, the specific C-O cleavage is commonly observed.6e, ${ }^{14}$ After early 
work based on copper-chromium oxide catalysts, bifunctional/bimetallic unsupported and supported heterogeneous systems were developed. ${ }^{15}$ Notably, in 2012 a general method for the hydrogenation of tertiary and secondary amides to amines with excellent selectivity using a bimetallic $\mathrm{Pd}-\mathrm{Re}$ catalyst was reported by Breit and coworkers. ${ }^{15 i}$ In addition, the groups of Kaneda, ${ }^{15}$ and later Shimizu, ${ }^{15 d}$ reported in 2017 bimetallic heterogeneous systems (PtV/HAP and $\mathrm{Re} / \mathrm{TiO}_{2}$, respectively) that are compatible with aromatic groups which are likewise reduced with most known heterogeneous systems. In spite of these improvements, the search for a general heterogeneous catalyst system with high efficiency, broad functional group selectivity and substrate scope is still ongoing.

Also most known homogeneous hydrogenation catalysts react with amides via the $\mathrm{C}-\mathrm{N}$ bond breaking route. ${ }^{11,} 16$ In recent years, especially metal pincer complexes with metal-ligand cooperation have proven to be suitable for such deaminative $\mathrm{C}$ $\mathrm{N}$ scissions. ${ }^{11,16-17}$ So far, just a few examples of organometallic complexes (mainly noble metal-based) have been disclosed for the homogenously-catalyzed deoxygenative hydrogenation of amides to amines (Scheme 2). Originally, investigations by ColeHamilton and co-workers, ${ }^{18}$ later extended by joint contributions with the groups of Leitner \& Klankermayer, ${ }^{19}$ have shown that ruthenium catalysts, modified by $1,1,1$ tris(diphenylphosphinomethyl)ethane L1 (so-called Triphos) as ligand, catalyze the deoxygenative hydrogenation of amides. Both the in situ generated system using $\left[\mathrm{Ru}(\mathrm{acac})_{3}\right] / T$ riphos, or the well-defined [(Triphos)Ru(tmm)] $(\mathrm{tmm}=$ trimethylenemethane) complex were used successfully for this transformation. ${ }^{18-19}$

Furthermore, Klankermayer's group reported a related [Ru(Triphos-xyl)(tmm)] complex bearing a substituted Triphosxylyl ligand.20 Interestingly, this novel ruthenium catalyst showed superior activity for the hydrogenation of lactams. Around the same time, we demonstrated that the [Ru/Triphos (L1)] catalyst system, in combination with $\mathrm{Yb}(\mathrm{OTf})_{3}$ as an additive, allows for improved amide hydrogenations which follow the unusual hydrogenation pathway $C$ (Scheme 1). ${ }^{21}$ In this case, the initially formed hemiaminal, generates the alcohol and the lower amine by breaking the $\mathrm{C}-\mathrm{N}$ bond (pathway $\mathrm{B}$ ). Then, these compounds produce the higher amine via a hydrogen borrowing/autotransfer mechanism under acidic reaction conditions (pathway $\mathrm{C}$ ). Moreover, a combination of a $\left[\mathrm{Ru}(\mathrm{H})_{2}(\mathrm{CO})\right.$ (Triphos)] complex in the presence of catalytic amounts of $\mathrm{TsOH}$ and $\mathrm{BF}_{3} \cdot \mathrm{Et}_{2} \mathrm{O}$ was reported by Zhou's group as a selective catalyst system for the deoxygenative amide hydrogenation. ${ }^{22}$ Notably, in all these [Ru/Triphos]-based catalysts the presence of an acidic co-catalyst is required for catalytic performance. Usually, this additive provides a weakly coordinating counter anion $\left(\mathrm{CH}_{3} \mathrm{SO}_{3}{ }^{-}, \mathrm{CF}_{3} \mathrm{SO}_{3}{ }^{-}\right.$or $\left.\mathrm{NTf}_{2}{ }^{-}\right)$, which is thought to stabilize the active complex fragment $\left[\mathrm{Ru}(\text { Triphos) }]^{2+} .{ }^{29 b}, 23\right.$ Furthermore, it creates the optimal reaction medium $p K_{\mathrm{a}}$ to benefit the hydrogenation events.
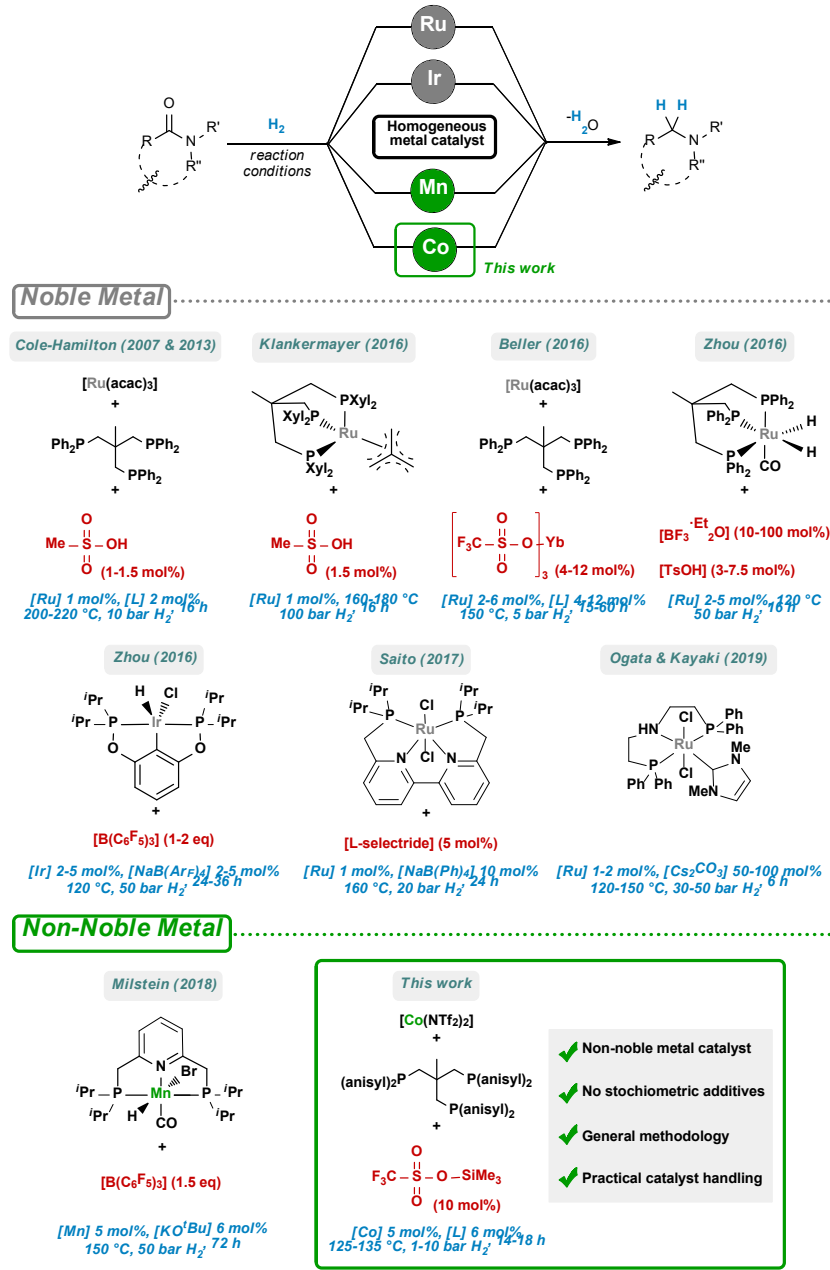

Scheme 2 Reported homogeneous metal-based catalytic systems for the selective deoxygenative hydrogenation of amides to obtain higher amines (cyclic amines are obtained from lactams).

Recently, four novel well-defined iridium, ${ }^{24}$ ruthenium ${ }^{16 i,}{ }^{25}$ and manganese ${ }^{26}$ pincer complexes have been successively developed by the groups of Zhou, Saito, Ogata \& Kayaki and Milstein, respectively. ${ }^{27}$ Whilst the iridium- and manganesebased complexes show remarkable catalytic activity for the deoxygenative hydrogenation of a wide range of amides but stoichiometric amounts of the expensive Lewis acid $\left[\mathrm{B}\left(\mathrm{C}_{6} \mathrm{~F}_{5}\right)_{3}\right](1$ to 1.5 equiv. with respect to the amide derivative) are required. ${ }^{24,26}$ On the other hand, the ruthenium pincer complex reported by Saito was only applied for the deoxygenative hydrogenation of $\varepsilon$-caprolactame, while the addition of catalytic amounts of two different boron co-additives $\left(\mathrm{NaB}(\mathrm{Ph})_{4}\right.$ and L-selectride) was needed. ${ }^{16 i}$ In particular, this bipyridylbased ruthenium complex was preceded by a closely related system described from the same group in 2013 , which exhibited a similar catalytic activity for the deoxygenative hydrogenation of several lactams. ${ }^{16 s}$ In this case, the authors tentatively attributed that the formation of the $\mathrm{C}-\mathrm{O}$ cleavage product is the result of a hydrogenation/C-N cleavage/hydrogen borrowing sequence of the secondary lactam. This assumption is in agreement with the more recent findings with the $\left[\mathrm{Ru} / \operatorname{Triphos}(\mathbf{L 1}) / \mathrm{Yb}(\mathrm{OTf})_{3}\right]$ system vide supra. ${ }^{21}$ Finally, Ogata \& 
Kayaki ${ }^{25}$ presented a ruthenium pincer catalyst that enables the formal deoxygenative hydrogenation of benzofused and nonfused lactams, including a wide range of unprotected substrates. Interestingly, in this contribution the authors prove that the observed C-O selectivity is actually attributed to a C-N hydrogenolysis/hydrogen borrowing mechanism (see Scheme 1, pathway C).

Despite all these recent efforts for homogeneous deoxygenative amide hydrogenations, the development of more economically viable and environmental-friendly general catalytic systems in this area is highly desirable. ${ }^{6 b-g}$

The replacement of precious metals with earth abundant and bio-relevant non-noble metals is a real goal in homogeneous catalysis and in organometallic chemistry. ${ }^{17 d, 28}$ In this direction, elegant examples of iron-, $28 \mathrm{~b}, 29$ cobalt- ${ }^{17,} 29-30$ and even manganese-based ${ }^{17 b}, 17 d, 31$ homogeneous hydrogenation catalysts have been successfully reported in the last years. Additionally, the use of molecular cobalt Triphos complexes for reductive processes involving carboxylic acids and related derivatives has attracted interest. Thus in 2015, the groups of de Bruin and Elsevier originally reported the first 3d metal catalyst able to hydrogenate carboxylic acids using $\left[\mathrm{Co}\left(\mathrm{BF}_{4}\right)_{2} \cdot 6 \mathrm{H}_{2} \mathrm{O} /\right.$ Triphos (L1)]. ${ }^{32}$ Later on, the reductive alkoxylation of cylic imides with alcohols to the corresponding alkoxy substituted derivatives applying the same catalyst was reported. ${ }^{33}$ Beyond this, $\mathrm{CO}_{2}$ hydrogenation to methanol ${ }^{34}$ or dialkoxymethane ethers, ${ }^{35}$ and the reductive C-alkylation of indoles ${ }^{36}$ and $\mathrm{N}$-alkylation of amines with carboxylic acids ${ }^{37}$ was realized using modified related cobalt catalysts making use of Triphos-type ligands.

Encouraged by these previous findings, and taking into account the unique activity revealed by $\mathrm{Ru} /$ Triphos related catalysts for amide hydrogenation (see Scheme 2), 18-22 we envisaged the development of related cobalt catalysts. Herein, we report for the first time, the selective deoxygenative hydrogenation of amides to amines, catalyzed by a non-noble metal under relatively mild conditions. Advantageously, (over)stoichiometric amounts of acid additives are not required in these transformations. In addition, the cobalt catalytic system is remarkably stable and can be handled even under air.

\section{Results and discussion}

As a starting point of our present investigation we chose the hydrogenation of benzanilide (1) as a benchmark reaction (Table 1). Inspired by the previously described cobalt-based catalytic systems for reductive processes involving carboxylic acid and related derivatives vide supra, initially $\left[\mathrm{Co}\left(\mathrm{BF}_{4}\right)_{2} \cdot 6 \mathrm{H}_{2} \mathrm{O}\right]$ (4 mol\% Co), in combination with ligand $\mathbf{L} 1$ (2 equiv to $\mathrm{Co}$ ), was tested under $\mathrm{H}_{2}$ (20 bar) at $145^{\circ} \mathrm{C}$ using $n$-butyl ether as solvent over $18 \mathrm{~h}$ (Table 1, entry 1 ). Unfortunately, only low conversion was reached and the undesired $\mathrm{C}-\mathrm{N}$ cleavage products aniline (3) and benzyl alcohol (4) were mainly detected, along with traces of the desired product $\mathrm{N}$-benzylaniline (2) (Table 1, entry $1)$.
Table 1 Cobalt-catalysed hydrogenation of benzanilide (1a): initial screening of the reaction conditions.

\begin{tabular}{|c|c|c|c|c|c|}
\hline${ }_{\mathrm{H}^{-}}^{\mathrm{O}}$ & 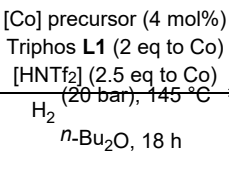 & $\mathrm{Ph}$ & + & $-\mathrm{NH}_{2}$ & $\mathrm{Ph} /$ \\
\hline Entry $^{a}$ & [Co] precursor & Conv. $^{b}(\%)$ & $2^{b}(\%)$ & $3^{b}(\%)$ & $4^{b}(\%)$ \\
\hline $1^{c}$ & $\mathrm{Co}\left(\mathrm{BF}_{4}\right)_{2} \cdot 6 \mathrm{H}_{2} \mathrm{O}$ & $<10$ & 2 & 7 & 7 \\
\hline 2 & $\mathrm{Co}\left(\mathrm{BF}_{4}\right)_{2} \cdot 6 \mathrm{H}_{2} \mathrm{O}$ & 83 & 32 & 51 & 51 \\
\hline 3 & $\mathrm{Co}\left(\mathrm{NTf}_{2}\right)_{2}$ & 95 & 46 & 49 & 49 \\
\hline $4^{c}$ & $\mathrm{Co}\left(\mathrm{NTf}_{2}\right)_{2}$ & 50 & 15 & 35 & 35 \\
\hline 5 & $\mathrm{Co}(\mathrm{acac})_{2}$ & 52 & 14 & 34 & 33 \\
\hline 6 & $\mathrm{Co}\left(\mathrm{F}_{6} \text {-acac }\right)_{2}$ & 15 & 7 & 7 & 7 \\
\hline 7 & $\mathrm{Co}(\mathrm{acac})_{3}$ & 31 & 9 & 20 & 20 \\
\hline 8 & $\mathrm{Co}(\mathrm{OAc})_{2} \cdot 4 \mathrm{H}_{2} \mathrm{O}$ & 77 & 23 & 49 & 50 \\
\hline 9 & $\mathrm{Co}\left(\mathrm{NO}_{3}\right)_{2} \cdot 6 \mathrm{H}_{2} \mathrm{O}$ & - & - & - & - \\
\hline 10 & $\mathrm{Co}\left(\mathrm{ClO}_{4}\right)_{2} \cdot 6 \mathrm{H}_{2} \mathrm{O}$ & $<5$ & - & - & - \\
\hline 11 & $\mathrm{CoF}_{2}$ & 67 & 29 & 35 & 35 \\
\hline 12 & $\mathrm{CoCl}_{2}$ & - & - & - & - \\
\hline 13 & $\mathrm{CoBr}_{2} \cdot 6 \mathrm{H}_{2} \mathrm{O}$ & - & - & - & - \\
\hline $14^{d}$ & $\mathrm{Co}\left(\mathrm{NTf}_{2}\right)_{2}$ & - & - & - & - \\
\hline $15^{c, d}$ & $\mathrm{Co}\left(\mathrm{NTf}_{2}\right)_{2}$ & - & - & - & - \\
\hline $16^{e}$ & - & - & - & - & - \\
\hline $17^{f}$ & $\mathrm{Co}\left(\mathrm{NTf}_{2}\right)_{2}$ & $>99$ & 38 & 61 & 61 \\
\hline $18^{g}$ & $\mathrm{Co}\left(\mathrm{NTf}_{2}\right)_{2}$ & 91 & 39 & 51 & 51 \\
\hline $19^{h}$ & $\mathrm{Co}\left(\mathrm{NTf}_{2}\right)_{2}$ & 78 & 23 & 54 & 54 \\
\hline
\end{tabular}

a Standard reaction conditions: benzanilide (1) $(50.3 \mathrm{mg}, 0.25 \mathrm{mmol}), \mathrm{Co}$ precatalyst ( $0.01 \mathrm{mmol}, 4 \mathrm{~mol} \%)$, Triphos (L1) $(0.02 \mathrm{mmol}, 8 \mathrm{~mol} \%, 2$ equiv to $\mathrm{Co}$ ), [HNTf ${ }_{2}$ ] $(0.025 \mathrm{mmol}, 10 \mathrm{~mol} \%, 2.5$ equiv to $\mathrm{Co}), n-\mathrm{Bu}_{2} \mathrm{O}(2 \mathrm{~mL})$ and $\mathrm{H}_{2}(20 \mathrm{bar})$ at $145{ }^{\circ} \mathrm{C}$ during 18 h. ${ }^{b}$ Conversion of $\mathbf{1}$ and yield of products 2, 3 and $\mathbf{4}$ were determined by gas chromatography using flame ionization detector (GC-FID) and $n$-hexadecane as an internal standard. ${ }^{c}$ Run without $\mathrm{HNTf}_{2} .{ }^{d}$ Run without ligand L1. ${ }^{e}$ Run without $\left[\mathrm{Co}\left(\mathrm{NTf}_{2}\right)_{2}\right] .{ }^{f}$ Run at 40 bar of $\mathrm{H}_{2} .{ }^{g}$ Run at 15 bar of $\mathrm{H}_{2} .{ }^{h}$ Run at $130{ }^{\circ} \mathrm{C}$ and 10 bar of $\mathrm{H}_{2}$.

Previous hydrogenation studies involving carboxylic acid derivatives or $\mathrm{CO}_{2}$ revealed the crucial requirement of an acid additive for catalytic activity. ${ }^{19-23,34-36,38}$ For instance, we recently disclosed that for the [Co/Triphos (L1)]-catalyzed $\mathrm{CO}_{2}$ hydrogenation to methanol, small amounts of triflimidic acid $\left[\mathrm{HNTf}_{2}\right]$ are required to form the active catalyst species. ${ }^{34 a}$ Therefore, we decided to explore the hydrogenation of $\mathbf{1}$ in the presence of [ $\mathrm{HNTf}_{2}$ ] (2.5 equiv. to $\mathrm{Co}$ ) as an acid additive.

Beneficially, the combination of $\left[\mathrm{Co}\left(\mathrm{BF}_{4}\right)_{2} \cdot 6 \mathrm{H}_{2} \mathrm{O} / \mathrm{LI}\right]$ and $\mathrm{HNTf}_{2}$ enhanced the conversion of 1 , affording $32 \%$ yield of the desired amine $\mathbf{2}$ (Table 1, entry 2). Taking into account that this improved activity might be attributed to the in situ formation of $\left[\mathrm{Co}\left(\mathrm{NTf}_{2}\right)_{2}\right]$, we tested this pre-catalyst. Indeed, $\left[\mathrm{Co}\left(\mathrm{NTf}_{2}\right)_{2} / \mathrm{L} \mathbf{1}\right]$ in combination of $\mathrm{HNTf}_{2}$ afforded almost quantitative conversion of 1 , with $46 \%$ yield of 2 (Table 1 , entry 3 ). As observed for $\left[\mathrm{Co}\left(\mathrm{BF}_{4}\right)_{2} \cdot 6 \mathrm{H}_{2} \mathrm{O} / \mathrm{L1}\right]$, worse results were obtained using [Co(NTf $\left.)_{2} / \mathbf{L 1}\right]$ in the absence of $\mathrm{HNTf}_{2}$ (Table 1, entry 4). Next, other cobalt salts featuring different counteranions (Table 1, entries 5-13) were tested in combination with Triphos under the same conditions; however, all catalyst systems afforded poorer results compared to [Co(NTf $\left.)_{2}\right]$. As expected, in the absence of $\mathbf{L} \mathbf{1}$ or a cobalt precursor no conversion was observed 
(Table 1, entries 14-16). Both higher (40 bar) and lower (15 bar) hydrogen pressure and/or temperature were detrimental for the yield of $\mathbf{2}$ (Table 1, entries $17-19$ ). For example, at $130^{\circ} \mathrm{C}$ lower conversion was obtained with decreased selectivity, which shows that the different reaction pathways (hydrogenolysis versus hydrogenation) have a different temperature influence. In case of pressure, the effects are less pronounced.

To improve the selectivity towards $\mathbf{2}$, we studied the catalytic activity of the $\left[\mathrm{Co}\left(\mathrm{NTf}_{2}\right)_{2} / \mathrm{HNTf}_{2}\right]$ system in combination with a series of mono- and multi-dentate phosphine ligands (Table S1). Among the $>20$ different phosphine ligands tested, only Triphos (L1) and related tridentate derivatives (L2, L3, L4 and L7) afforded significant activity (Table 2), while all the other ligands remained inactive. Compared to the parent Triphos, L2 ( $p$-tolyl) and L3 ( $p$-anisole) slightly improved the amide conversion and yield of the desired higher amine (Table 2, entries 2 and 3); however, L4 ( $p$-aminodimethylphenyl), L5 ( $m$-xylyl), and L6 (1naphthyl) were shown to be as inactive for the hydrogenation of the benchmark amide 1 under the same conditions (Table 1 , entries 4-6, respectively). When the most active ligands $\mathbf{L} 2$ and L3 were compared under milder reaction conditions for benzanilide $(\mathbf{1})$ hydrogenation $\left(135^{\circ} \mathrm{C}\right.$ and 10 bar of $\left.\mathrm{H}_{2}\right)$, L3 was noticed to be superior to $\mathbf{L} \mathbf{2}$ (55\% yield of $\mathbf{2}$, Table 2 , entries 8 and 9). ${ }^{37 b}$

Due to the crucial role of the acid additive (Lewis or Brönsted), ${ }^{19-}$ 23, 34-36, 38 further acid additives were employed for

Table 2 Cobalt-catalysed hydrogenation of benzanilide (1): study with different Triphostype ligands.

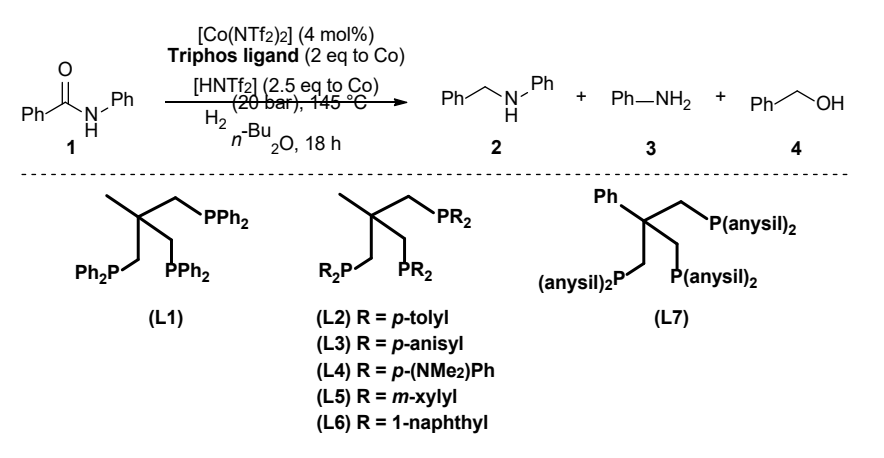

\begin{tabular}{cccccc}
\hline Entry $^{a}$ & Triphos Ligand & Conv. $^{b}(\%)$ & $\mathbf{2}^{b}(\%)$ & $\mathbf{3}^{b}(\%)$ & $\mathbf{4}^{b}(\%)$ \\
\hline 1 & $(\mathbf{L 1})$ & 95 & 46 & 49 & 49 \\
2 & $(\mathbf{L 2})$ & $>99$ & 52 & 48 & 48 \\
3 & $(\mathbf{L 3})$ & $>99$ & 52 & 48 & 48 \\
4 & $(\mathbf{L 4})$ & - & - & - & - \\
5 & $(\mathbf{L 5})$ & $<5$ & 2 & 3 & 3 \\
6 & $(\mathbf{L 6})$ & - & - & - & - \\
7 & $(\mathbf{L 7})$ & $>99$ & 44 & 55 & 55 \\
$8^{c}$ & $(\mathbf{L})$ & 69 & 48 & 21 & 20 \\
$9^{c}$ & $(\mathbf{L 3})$ & $>99$ & 55 & 45 & 44
\end{tabular}

a Standard reaction conditions: benzanilide (1) $(50.3 \mathrm{mg}, 0.25 \mathrm{mmol}),\left[\mathrm{Co}\left(\mathrm{NTf}_{2}\right)_{2}\right.$ ] precatalyst ( $0.01 \mathrm{mmol}, 4 \mathrm{~mol} \%)$, Triphos ligand $(0.02 \mathrm{mmol}, 8 \mathrm{~mol} \%, 2$ equiv. to Co), [ $\mathrm{HNTf}_{2}$ ] ( $0.025 \mathrm{mmol}, 10 \mathrm{~mol} \%, 2.5$ equiv. to $\left.\mathrm{Co}\right), n-\mathrm{Bu}_{2} \mathrm{O}(2 \mathrm{~mL})$ and $\mathrm{H}_{2}$ (20 bar) at $145{ }^{\circ} \mathrm{C}$ during $18 \mathrm{~h} .{ }^{b}$ Conversion of $\mathbf{1}$ and yield of products 2,3 and $\mathbf{4}$ were determined by gas chromatography using flame ionization detector (GC-FID) and $n$-hexadecane as an internal standard. ${ }^{c}$ Run at $\mathrm{H}_{2}(10 \mathrm{bar})$ and $135^{\circ} \mathrm{C}$. the hydrogenation of 1 using the optimal [ $\mathrm{Co}\left(\mathrm{NTf}_{2}\right)_{2} / \mathrm{L} 3$ ] system (Figure 1). This survey of more than 35 commercially available acid additives included Brönsted (acetic, trifluoroacetic, triflic, methanesulfonic, $p$-toluenesulfonic and tetrafluoroboric acid, marked in red) and Lewis acid additives comprising boron-based species $\left[\mathrm{BCl}_{3}, \mathrm{~B}\left(\mathrm{C}_{6} \mathrm{~F}_{5}\right)_{3}, \mathrm{BF}_{3} \cdot \mathrm{Et}_{2} \mathrm{O}\right.$, marked in orange], triflimidates $\left[\mathrm{X}^{\mathrm{n}+}\left(\mathrm{NTf}_{2}\right)_{n} ; \mathrm{X}^{\mathrm{n}+}=\mathrm{Mn}^{+}, \mathrm{Ag}^{+}, \mathrm{Li}^{+}\right.$, marked in green $]$as well as triflates $\left[\mathrm{X}^{\mathrm{n}+}(\mathrm{OTf})_{n} ; \mathrm{X}^{\mathrm{n}+}=\mathrm{Li}^{+}, \mathrm{Me}_{3} \mathrm{Si}^{+}, \mathrm{Me}^{+}, \mathrm{Zn}^{2+}, \mathrm{Ga}^{2+}, \mathrm{Fe}^{2+}, \mathrm{Mg}^{2+}\right.$, $\mathrm{Ni}^{2+}, \mathrm{Tb}^{3+}, \mathrm{Ce}^{3+}, \mathrm{Yb}^{3+}, \mathrm{Al}^{3+}, \mathrm{Mn}^{3+}, \mathrm{Fe}^{3+}, \mathrm{Sc}^{3+}, \mathrm{Sn}^{3+}, \mathrm{In}^{3+}, \mathrm{Ho}^{3+}, \mathrm{Sm}^{3+}$, $\mathrm{Eu}^{3+}, \mathrm{Dy}^{3+}, \mathrm{Pr}^{3+}, \mathrm{La}^{3+}$ and $\mathrm{Hf}^{4+}$, marked in blue]. In general, Brønsted acids presented moderate activities (HOTf, MSA, $\left.\mathrm{HBF}_{4} \cdot \mathrm{Et}_{2} \mathrm{O}, \mathrm{HNTf}_{2}\right)$, while triflate-based derivatives such as [ $\mathrm{Me}_{3} \mathrm{SiOTf}$ ], [MeOTf], [Al(OTf $)_{3}$ ], [Fe(OTf) ${ }_{3}$ ], [Sn(OTf $\left.)_{3}\right],\left[\ln (\mathrm{OTf})_{3}\right.$ ] and $\left[\mathrm{Dy}(\mathrm{OTf})_{3}\right]$ showed superior performance than the other additives (Figure 1). The best yield (69\%) of the desired amine 2 was obtained in the presence of [ $\mathrm{Me}_{3} \mathrm{SiOTf}$ ] (TMSOTf), which to the best of our knowledge wasn't previously reported as suitable additive in this transformation. In contrast, boron Lewis acid additives such as $\left[\mathrm{BCl}_{3}\right],\left[\mathrm{B}\left(\mathrm{C}_{6} \mathrm{~F}_{5}\right)_{3}\right]$ and $\left[\mathrm{BF}_{3} \cdot \mathrm{Et}_{2} \mathrm{O}\right]$ produced lower yields of 2. Surprisingly, the $\left[\mathrm{Co}\left(\mathrm{NTf}_{2}\right)_{2} / \mathrm{L3}\right]$ system in combination with $\left[\mathrm{Yb}(\mathrm{OTf})_{3}\right.$ ] generated only small amounts of amine 2 (Figure $1,<10 \%$ ), which is in contrast to the results obtained in previous studies with [Ru/Triphos(L1)] system. ${ }^{21}$

Next, the influence of critical parameters (solvent, hydrogen pressure, temperature, and the relative amounts of $\left[\mathrm{Co}\left(\mathrm{NTf}_{2}\right)_{2}\right]$, ligand $\mathbf{L} 3$ and [ $\left.\mathrm{Me}_{3} \mathrm{SiOTf}\right]$ additive) on the model reaction was investigated systematically in the presence of the best additive ( $\left.\mathrm{Me}_{3} \mathrm{SiOTf}\right)$ and $\left[\mathrm{Co}\left(\mathrm{NTf}_{2}\right)_{2} / \mathrm{L} 3\right]$. Testing different solvents (ethers, arenes, halogen-containing, alkanes, and alcohols) revealed a positive influence of nonpolar reaction media, ${ }^{16 \mathrm{~h},} 39$ with $n$-heptane leading to the best results (Figure S1). As shown in Figure S2, a high yield of the desired amine $\mathbf{2}$ was obtained using $5 \mathrm{~mol} \%$ of cobalt precursor and a $1 / 1.2$ molar ratio of [Co( $\left(\mathrm{NTf}_{2}\right)_{2} / \mathrm{L} 3$ ] at 10 bar pressure and $125^{\circ} \mathrm{C}$. Applying slightly higher temperature and lower pressure $\left(135^{\circ} \mathrm{C}\right.$ and 5 bar of $\left.\mathrm{H}_{2}\right)$ gave similar results. Variation of the relative amount of additive was detrimental for the yield of $\mathbf{2}$. Hence, under optimal conditions, full conversion of $\mathbf{1}$ and an $80 \%$ yield of $\mathbf{2}$ were achieved.

Remarkably, the selective hydrogenation preceded with good yield and selectivity even using only 1 bar of $\mathrm{H}_{2}$. To the best of our knowledge no homogeneous catalyst system has been described for amide reduction with molecular hydrogen under such mild conditions and it seems that these conditions aren't compatible with the well-known Ru/Triphos system previously used for this reaction (Table 4).

Thus, to better understand this improved homogeneous cobaltcatalyzed deoxygenative hydrogenation of amides, a set of control experiments were carried out (Scheme 3). Firstly, we performed an experiment using aniline (3) and benzyl alcohol (4) as starting materials (Scheme 3a) to provide evidence of a $\mathrm{C}-\mathrm{N}$ breaking/hydrogen borrowing sequence similar to the one reported for [Ru/Triphos(L1)/Yb]. ${ }^{21}$ Remarkably, $\mathrm{N}$-alkylation of $\mathbf{3}$ with $\mathbf{4}$ only gave very small amounts of the alkylated amine $\mathbf{2}$ under 5 bar pressure of $\mathrm{H}_{2}$ or $\mathrm{N}_{2}$. 

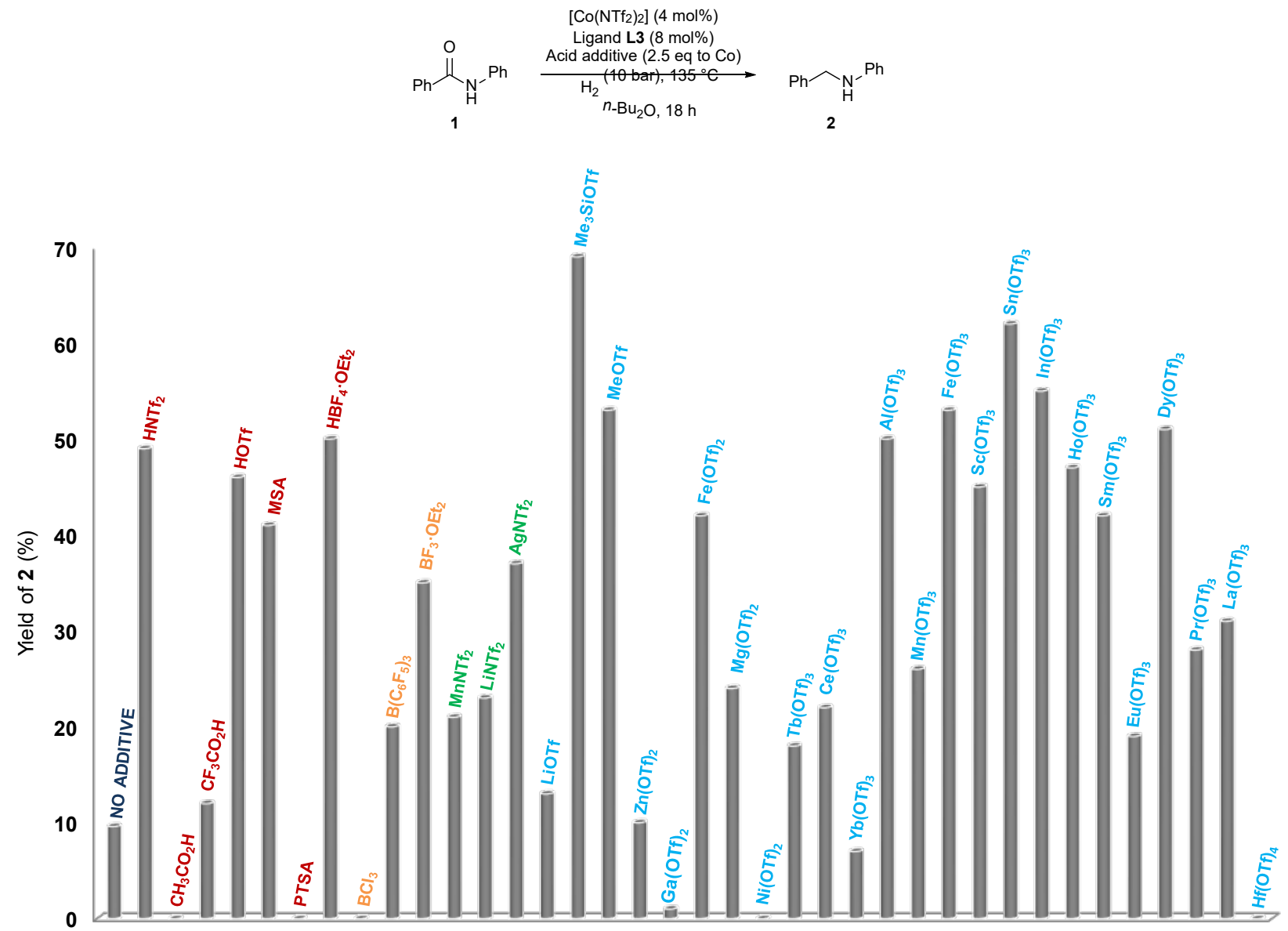

Figure 1 Evaluation of the catalytic activity of different acid additives in the hydrogenation of benzanilide (1) with the [Co(NTf $\left.)_{2} / \mathbf{L} 3\right]$ system: Yield of amine $\mathbf{2}$ in the presence of each acid additive. Standard reaction conditions: benzanilide (1) $(50.3 \mathrm{mg}, 0.25 \mathrm{mmol})$, [Co( $\left.\mathrm{NTf}_{2}\right)_{2}$ ] $(0.01 \mathrm{mmol}, 4 \mathrm{~mol} \%)$, ligand $\mathbf{L 3}(0.02 \mathrm{mmol}, 8 \mathrm{~mol} \%, 2$ equiv. to Co), acid additive $(0.025$ mmol, $10 \mathrm{~mol} \%, 2.5$ equiv. to $\mathrm{Co}), n-\mathrm{Bu}_{2} \mathrm{O}(2 \mathrm{~mL})$ and $\mathrm{H}_{2}(10 \mathrm{bar})$ at $135^{\circ} \mathrm{C}$ during $18 \mathrm{~h}$. Yield of product 2 was determined by gas chromatography using flame ionization detector (GC-FID) and $n$-hexadecane as an internal standard. In all cases, only the alcohol and amine arising from the $\mathrm{C}-\mathrm{N}$ bond cleavage were detected as by-product.

Similar results were obtained starting from benzaldehyde in the presence of a slight excess of aniline (3) (Scheme 3b). Both experiments exclude an initial $\mathrm{C}-\mathrm{N}$ hydrogenolysis, with the formation of benzaldehyde (5) or benzyl alcohol (4) and aniline (3) as the major reaction pathway. Interestingly, employing aldimine (6) as a starting material, both with and without $\mathrm{Me}_{3} \mathrm{SiOTf}$ (Scheme $3 \mathrm{c}$ ), gave amine 2 in $75 \%$ and $69 \%$ yield, respectively.

This shows the importance of the acidic additive in the first reduction step of the amide and not in the final hydrogenation. Moreover, a competition experiment under our standard reaction conditions was carried out by reacting benzanilide (1) in the presence of 1 equiv. of 4-methylbenzyl alcohol (7) (Scheme 3d). As expected, benzanilide (1) was almost fully converted and the major product observed was $N$-benzyl aniline (2). At the same time, the $\mathrm{N}$-alkylated amine $\mathbf{8}$ and the imine $\mathbf{9}$, both products arising of the alkylation of 4-methylbenzyl alcohol, were detected to a minor extent. Evidently, $\mathbf{8}$ and $\mathbf{9}$ are not formed via direct $\mathrm{N}$-alkylation (Scheme 3a), but instead apparently the aldimine or the aminal underwent alkylation in the presence of 1 equiv. of 4-methylbenzyl alcohol (7) to give 8 and $\mathbf{9}$. Indeed, reacting $\mathbf{6}$ with $\mathbf{7}$ yielded $\mathbf{8}$ in a similar quantity as above (Scheme 3e).
Based on these experiments, we believe that the aldimine 6 is a likely intermediate of this cobalt-catalyzed amide hydrogenation (Scheme 4). Nevertheless, other reaction pathways cannot be excluded.

Next, to characterize potential catalytically active species, [Co(NTf $\left.)_{2}\right)_{2}$ and ligand $\mathbf{L} 3$ were mixed in a $1 / 1.2$ molar ratio in toluene and stirred at room temperature overnight (see $\mathrm{SI}$ ). Subsequently a dark brown powder was formed which could be assigned to [Co/(L3)/F]NTf ${ }_{2}$ according to HR-MS. Unfortunately, many crystallization attempts failed and we were unable to get a crystal structure due to the high level of disorder of the triflimide anion. Fortunately, using $\left[\mathrm{Co}\left(\mathrm{BF}_{4}\right)_{2} \cdot 6 \mathrm{H}_{2} \mathrm{O}\right]$ as a precursor showed similar catalytic activity compared to [Co( $\left(\mathrm{NTf}_{2}\right)_{2}$ ] and we were successful in obtaining crystals appropriate for X-ray analysis. As shown in Figure 2, a fluoridebridged dimeric species [Co(L3)F $]_{2}\left(\mathbf{B F}_{4}\right)_{2}$ is formed.

This complex performed the hydrogenation of $\mathbf{1}$ under the optimized conditions similar to the in situ system. In fact, the desired product $\mathbf{2}$ was obtained in 70\% yield and even better selectivity (86\%). Reaction of this dimeric complex [Co(L3)F $]_{2}\left(\mathrm{BF}_{4}\right)_{2}$ with 4 equiv. of [Me $\left.3 \mathrm{SiOTf}\right]$ in THF at $70{ }^{\circ} \mathrm{C}$ afforded a cobalt complex which could be assigned to [Co/(L3)/OTf]OTf according to HR-MS. 
(a)

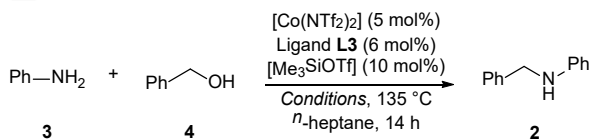

$$
\begin{aligned}
& \text { (1.5 eq) } \\
& \begin{array}{ccc}
\text { Conditions }^{a} & \text { Conv. } \mathbf{4}(\%)^{b} & \text { Yield } \mathbf{2}(\%)^{b} \\
\hline \mathrm{H}_{2}{ }^{(5 \mathrm{bar})} & 10 & 2 \\
\mathrm{~N}_{2}{ }^{(5 \mathrm{bar})} & 15 & 4
\end{array}
\end{aligned}
$$

(b)

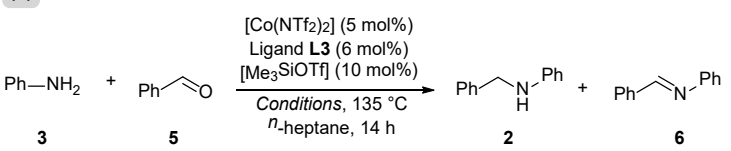

$$
\begin{aligned}
& \text { (1.5 eq) }
\end{aligned}
$$

\begin{tabular}{|c|c|c|c|c|}
\hline $\mathrm{Ph} \widehat{>}_{\mathrm{N}^{-}} \mathrm{Ph}$ & 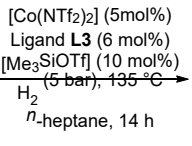 & $\mathrm{Ph} \widehat{\mathrm{N}^{-}}$ & $\mathrm{Ph}-\mathrm{NH}_{2}$ & $\mathrm{Ph}^{-}$ \\
\hline conditions & Conv. 6 (\%)[b] & Yield $\mathbf{2}(\%)[b]$ & Yield 3 (\%)[b] & Yield $\mathbf{4}(\%)[b]$ \\
\hline standard & $>99$ & 75 & 22 & 15 \\
\hline without ${ }_{\left[\mathrm{Me}_{3} \mathrm{SiC}\right.}$ & iOTf] & 69 & 20 & 15 \\
\hline
\end{tabular}

\begin{tabular}{cccc} 
Conditions $^{a}$ & Conv. 5 $(\%)^{b}$ & ${\text { Yield } \mathbf{2}(\%)^{b}}^{b}$ & Yield $\mathbf{6}(\%)^{b}$ \\
\hline $\mathrm{H}_{2}{ }^{(5 \mathrm{bar})}$ & $>99$ & 2 & 1 \\
$\mathrm{~N}_{2}{ }^{(5 \mathrm{bar})}$ & $>99$ & 1 & 15
\end{tabular}

(c) (d)

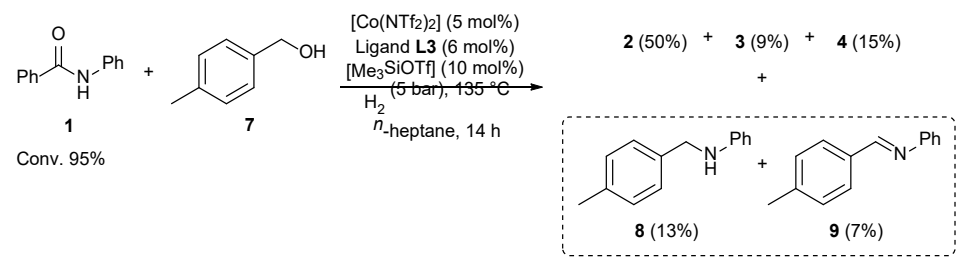

(e)

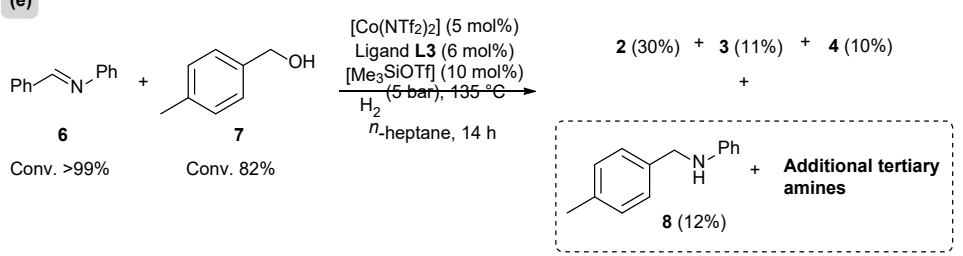

Scheme 3 Control experiments. ${ }^{a}$ Standard reaction conditions: benzyl alcohol (4), benzaldehyde (5), benzanilide (1) and N-phenylbenzylimine (6) (0.25 mmol), [Co(NTf $\left.)_{2}\right](0.0125$ mmol, 5 mol\%), ligand L3 ( $0.015 \mathrm{mmol}, 6 \mathrm{~mol} \%, 1.2$ equiv. to Co), [Me SiOTf] ( $0.025 \mathrm{mmol}, 10 \mathrm{~mol} \%, 2$ equiv. to Co), $n$-heptane ( $2 \mathrm{~mL}$ ) and $\mathrm{H}_{2}$ or $\mathrm{N}_{2}(5 \mathrm{bar})$ at $135{ }^{\circ} \mathrm{C}$ during $14 \mathrm{~h}$. ${ }^{b}$ Conversion of starting material and yield of products were determined by gas chromatography using flame ionization detector (GC-FID) and $\mathrm{n}$-hexadecane as an internal standard.

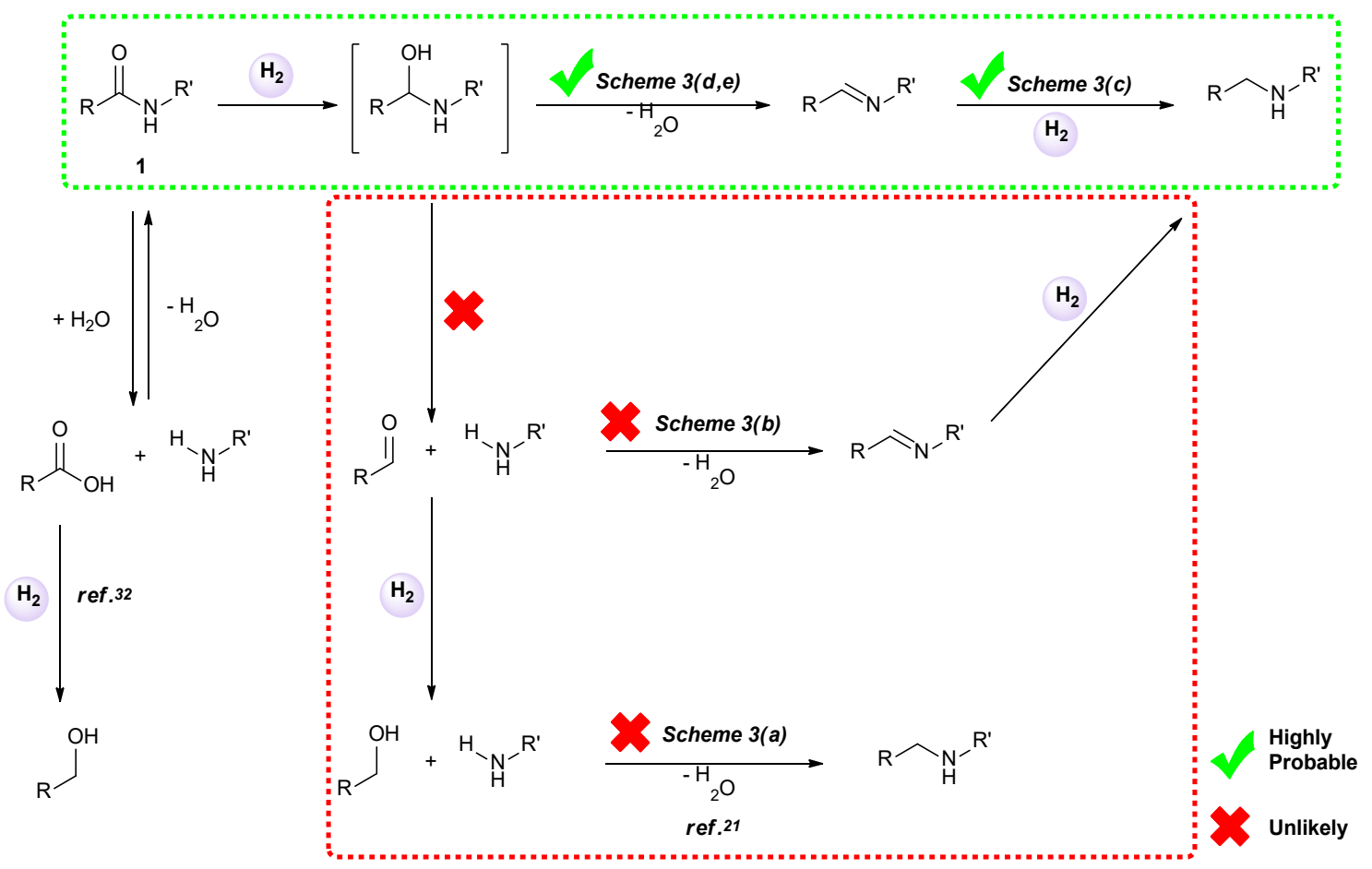

Scheme 4 Proposed reaction mechanism for the $\left[\mathrm{Co}\left(\mathrm{NTf}_{2}\right)_{2} / \mathrm{L} 3 / \mathrm{Me}_{3} \mathrm{SiOTf}\right]$-catalyzed deoxygenative hydrogenation of amides to amines. 


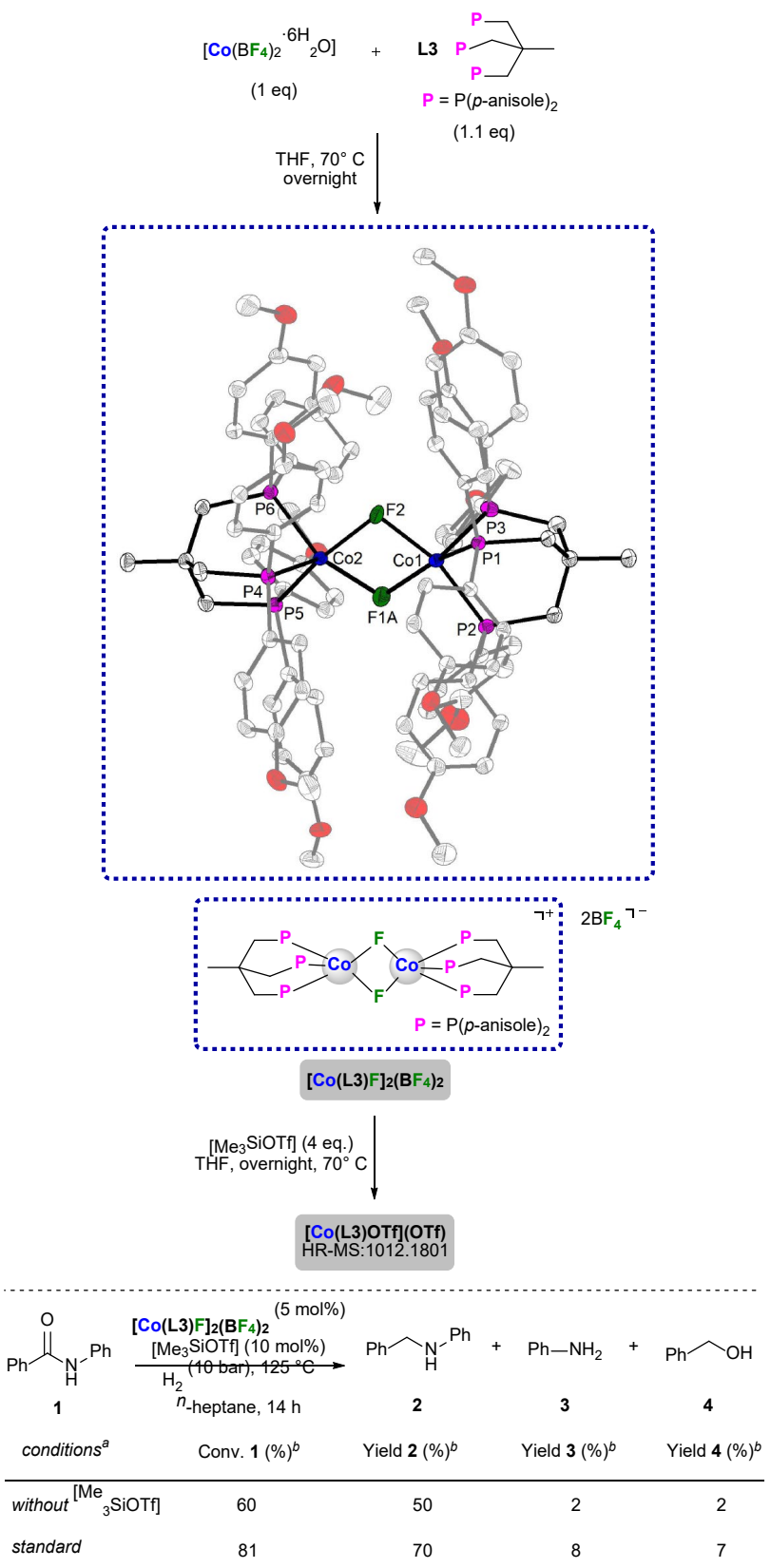

Figure 2 (Top) In situ formation of $\left[\mathrm{Co}(\mathrm{L} 3) \mathrm{F}_{2}\left(\mathrm{BF}_{4}\right)_{2}\right.$ and crystal structure. (Bottom) Evaluation of the catalytic activity of $\left[\mathrm{Co}\left(\mathrm{L}_{3}\right) \mathrm{F}_{2}\left(\mathrm{BF}_{4}\right)_{2}\right.$ in the hydrogenation of benzanilide (1). Molecular structure of the cation of $\left[\mathrm{Co}\left(\mathrm{L}_{3}\right) \mathrm{F}_{2}\left(\mathrm{BF}_{4}\right)_{2}\right.$ drawn with thermal ellipsoids at the $30 \%$ probability level. Hydrogen atoms and minor occupancy atoms are omitted for clarity. ${ }^{a}$ Standard reaction conditions: benzanilide (1) $(50.3 \mathrm{mg}, 0.25 \mathrm{mmol}$ ), [Co(L3)F $]_{2}\left(\mathrm{BF}_{4}\right)_{2}$ precatalyst $(0.0125 \mathrm{mmol}, 5 \mathrm{~mol} \%), n$-heptane $(2 \mathrm{~mL})$ and $\mathrm{H}_{2}(5$ bar) at $135{ }^{\circ} \mathrm{C}$ during 14 h. ${ }^{b}$ Conversion of $\mathbf{1}$ and yield of products $\mathbf{2 ,} \mathbf{3}$ and $\mathbf{4}$ were determined by gas chromatography using flame ionization detector (GC-FID) and $n$-hexadecane as an internal standard.

Table 3 Substrate scope for the cobalt-catalysed deoxygenative hydrogenation of amides.

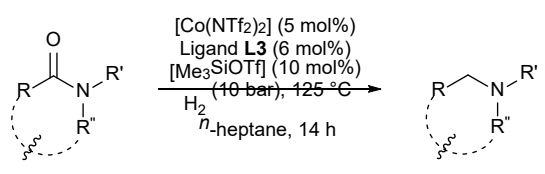

(2)

${ }^{a}$ Standard reaction conditions: amide or imide $(0.25 \mathrm{mmol}),\left[\mathrm{Co}\left(\mathrm{NTf}_{2}\right)_{2}\right](0.0125$ $\mathrm{mmol}, 5 \mathrm{~mol} \%$ ), ligand $\mathbf{L} \mathbf{3}(0.015 \mathrm{mmol}, 6 \mathrm{~mol} \%, 1.2$ equiv. to $\mathrm{Co})$, [Me $3 \mathrm{SiOTf}$ ] (0.025 $\mathrm{mmol}, 10 \mathrm{~mol} \%$, 2 equiv. to $\mathrm{Co}), n$-heptane $(2 \mathrm{~mL})$ and $\mathrm{H}_{2}(10 \mathrm{bar})$ at $125^{\circ} \mathrm{C}$ during $14 \mathrm{~h} .{ }^{b}$ Conversion of amides, yields of amines and product selectivity were determined by gas chromatography using flame ionization detector (GC-FID) and $n$-hexadecane as an internal standard. In all cases, only the alcohols and amines arising from the $\mathrm{C}-\mathrm{N}$ bond cleavage were detected as by-products. ${ }^{c}$ Run at $135^{\circ} \mathrm{C}$ and $18 \mathrm{~h} .{ }^{d}$ Isolated yield of the product after purification with column chromatography is given. ${ }^{e}$ Run with [Me $3 \mathrm{SiOTf}$ ( $0.03 \mathrm{mmol}, 12.5 \mathrm{~mol} \%, 2.5$ equiv. to $\mathrm{Co}$ ) at $145^{\circ} \mathrm{C}$ and $\mathrm{H}_{2}$ (15 bar) over $24 \mathrm{~h}$. 4-trifluoromethyldibenzylamine was also detected as by-product in a $50 \%$ yield. $f$ Run at $24 \mathrm{~h}, 1 \mathrm{H}$-indoline was detected in $<10 \%$ yield. ${ }^{g}$ Run at $18 \mathrm{~h}$.

Encouraged by the success in the deoxygenative hydrogenation of the benchmark substrate $\mathbf{1}$ (vide supra), we explored the 
reactivity of different amides under the preselected reaction conditions; all these reactions were run in heptane at 125 or 135 ${ }^{\circ} \mathrm{C}$ with 10 bar $\mathrm{H}_{2}$ for a standard reaction time of 14 hours (see Table 3). For poorly reacting substrates the reaction time was extended to improve both conversions and selectivities in the desired amines. In general, high conversions and moderate to good selectivities were obtained for both $\mathrm{N}$-aryl acet- and benzamides (Table 3, entries 1-12) except for 2-chloro acetanilide, whose amine yield was only $26 \%$ (Table 3 , entry 3 ). In some cases, small amounts of alcohol and amine by- products were detected, arising from $\mathrm{C}-\mathrm{N}$ hydrogenolysis of the amide. Overall, para-substituted acetanilides afforded higher yields than the corresponding meta- and ortho-substituted substrates, and no direct correlation between the electronic nature of the substituents and the amine yield became evident. Apparently, an increased steric hindrance seems to have a negative effect on the reactivity. Thus, the hydrogenation of 4-, 3-, and 2-methylacetanalide (Table 3, entries 5, 6 and 7) afforded $65 \%, 43 \%$, and $40 \%$ yield of amine products, respectively. Also, in case of $N$-1-naphthalenyl acetanilide the desired product yield was only $36 \%$ (Table 3 , entry 10 ).

In addition to acet- and benzanilides, 2-phenylacetanilide was hydrogenated in $70 \%$ yield with very good selectivity (Table 3 , entry 13).

Similarly, to previously known homogeneous Ru-based catalysts, ${ }^{18-19,} 21-22$ the hydrogenation of both primary and tertiary amides is more challenging. In fact, the hydrogenation of 4-trifluoromethylbenzamide resulted in quantitative conversion but generated only a low yield of the desired primary amine $(20 \%$, Table 3 , entry 14$)$.

As a special case, the hydrogenation of oxindole gave mainly $3 \mathrm{H}$ indole $48 \%$ yield (Table 3 , entry 15 ) due to the aromatic stabilization and $1 \mathrm{H}$-indoline was observed only in minor amounts $(<10 \%)$. On the other hand, unfortunately an aliphatic cyclic amide substrate such as $\varepsilon$-caprolactame did not afford any conversion to the desired product (Table 3 , entry 16 ).

Notably, the presented protocol can be applied to the hydrogenation of cyclic imides, too. In particular phthalimides ${ }^{40}$ are an important type of carboxylic acid derivative and several of these compounds show interesting biological activities. ${ }^{41}$ Among the possible products obtained from the reduction of phthalimides, $6 \mathrm{~g}, 40$ isoindolinones ${ }^{40,} 42$ and substituted derivatives ${ }^{33}, 38 c, 40,42 a$ are the most desired as they are valuable scaffolds in pharmaceuticals and agrochemicals, as well as relevant building blocks in organic synthesis; ${ }^{43}$ our protocol also enables the reduction of phthalimides in modest yield, but excellent selectivity to give isoindolinones (Table 3, entries 17 and 18). It is noteworthy to point out that homogeneous catalysts with the ability to perform this transformation in a regioselective fashion using molecular hydrogen are rare. ${ }^{40,42}$ Finally, we were interested comparing the catalytic activity of the $\left[\mathrm{Co}\left(\mathrm{NTf}_{2}\right)_{2} / \mathrm{L} \mathbf{3} / \mathrm{Me}_{3} \mathrm{SiOTf}\right]$ system with the previous state-ofthe-art $\left[\mathrm{Ru} / \operatorname{Triphos}(\mathrm{L1}) / \mathrm{Yb}(\mathrm{OTf})_{3}\right]^{21}$ catalyst for the hydrogenation of amides 1 .
Table 4 Cobalt vs ruthenium system in the hydrogenation of benzanilide (1).

\begin{tabular}{|c|c|c|c|c|}
\hline & 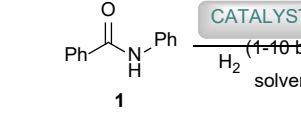 & $\begin{array}{l}\text { YSTEM } \\
125^{\circ} \mathrm{C} \longrightarrow \\
4 \mathrm{~h}\end{array}$ & $\mathrm{~N}^{\mathrm{H}^{-\mathrm{Ph}}}$ & \\
\hline & 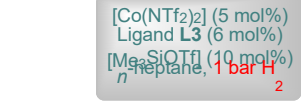 & $\begin{array}{c}{\left[\mathrm{Ru}(\mathrm{acac})_{3}\right]} \\
\text { Ligand L1 } \\
\text { [Yb(OTf) } 3] \\
\text { THF, } 1 \mathrm{~b}\end{array}$ & & \\
\hline & $\begin{array}{l}{ }^{b} \text { Conv.: }>99 \% \\
\text { Yield of 2: } 70 \%\end{array}$ & $\begin{array}{l}{ }^{b} \text { Conv.: } \\
\text { Yield of }\end{array}$ & & \\
\hline Entry $^{a}$ & {$[\mathrm{M}(\mathrm{mol} \%)] / \mathrm{L}(\mathrm{mol} \%) / \mathrm{add}$} & ve(mol\%) & Conv. $^{b}(\%)$ & $2^{b}(\%)$ \\
\hline 1 & {$\left[\mathrm{Co}\left(\mathrm{NTf}_{2}\right)_{2}(5) / \mathrm{L3}(6) / \mathrm{Me}\right.$} & OTf(10)] & $>99$ & 80 \\
\hline 2 & {$\left[\mathrm{Ru}(\mathrm{acac})_{3}(5) / \mathbf{L} 3(6) / \mathrm{Me}\right.$} & OTf(10)] & - & - \\
\hline $3^{c}$ & {$\left[\mathrm{Ru}(\mathrm{acac})_{3}(2) / \mathrm{L3}(4) / \mathrm{Yb}\right.$} & $\left.T f)_{3}(4)\right]$ & - & - \\
\hline $4^{c}$ & {$\left[\mathrm{Ru}\left(\mathrm{acac}_{3}(2) / \mathrm{L1}(4) / \mathrm{Yb}\right.\right.$} & $\left.\mathrm{Tf})_{3}(4)\right]$ & 46 & 4 \\
\hline $5^{c}$ & {$\left[\mathrm{Ru}(\mathrm{acac})_{3}(5) / \mathbf{L} \mathbf{3}(4) / \mathrm{Me}\right.$} & iOTf(4)] & 25 & 1 \\
\hline $6^{c}$ & {$\left[\mathrm{Ru}(\mathrm{acac})_{3}(2) / \mathbf{L 1}(4) / \mathrm{Me}\right.$} & iOTf(4)] & 80 & 17 \\
\hline $7^{d}$ & {$\left[\mathrm{Co}\left(\mathrm{NTf}_{2}\right)_{2}(5) / \mathrm{L} 3(6) / \mathrm{Me}\right.$} & OTf(10)] & 99 & 70 \\
\hline $8^{d}$ & {$\left[\mathrm{Ru}(\operatorname{acac})_{3}(2) / \mathrm{L1}(4) / \mathrm{Me}\right.$} & iOTf(4)] & 37 & 19 \\
\hline
\end{tabular}

a Standard reaction conditions: benzanilide (1) $(50.3 \mathrm{mg}, 0.25 \mathrm{mmol}),[\mathrm{M}]=$ [Co(NTf $)_{2}$ ] or [Ru(acac) $)_{3}$ ( 2 or 5 mol\%), ligand L1 or L3 (4 or 6 mol\%, 1.2 or 2 equiv. to metal), [Me ${ }_{3} \mathrm{SiOTf}$ ] or [Yb(OTf) 3 ] ( 4 or $10 \mathrm{~mol} \%, 0.8$ or 2 equiv. to metal), $n$-heptane $(2 \mathrm{~mL})$ and $\mathrm{H}_{2}(5 \mathrm{bar})$ at $135^{\circ} \mathrm{C}$ during $14 \mathrm{~h} .{ }^{b}$ Conversion of 1 and yield of product $\mathbf{2}$ was determined by gas chromatography using flame ionization detector (GC-FID) and $n$-hexadecane as an internal standard. ${ }^{c}$ Run using THF as solvent. ${ }^{d}$ Run at $\mathrm{H}_{2}$ (1 bar) during $36 \mathrm{~h}$.

Other homogeneous catalyst systems e.g. based on manganese have not been included because of the drastic reaction conditions necessary for such systems. As shown in Table 4, the current cobalt system performed the hydrogenation of benzanilide (1) with better yields of the desired higher amine $\mathbf{2}$ in comparison with the ruthenium system under identical conditions.

Obviously, this does not proof that the presented catalyst system always shows improved performance. However, also applying different combinations of $\left[\mathrm{Ru}(\mathrm{acac})_{3}\right]$ with $\mathbf{L} \mathbf{3}$ and/or $\mathrm{Me}_{3} \mathrm{SiOTf}$ as additive, did not improve the results. This behavior might be attributed to the fact that in the case of $\mathrm{Ru}$ as a catalyst, in situ $\mathrm{N}$-alkylation with the alcohol takes place, ${ }^{21}$ which is not the case in this novel cobalt-based process.

\section{Experimental details}

General procedure for the hydrogenation of benzanilide (1)

A $4 \mathrm{~mL}$ glass vial containing a stirring bar was sequentially charged with [Co( $\left.\left(\mathrm{NTf}_{2}\right)_{2}\right](7.7 \mathrm{mg}, 0.0125 \mathrm{mmol}, 5 \mathrm{~mol} \%)$, ligand L3 (12 mg, $0.015 \mathrm{mmol}, 6 \mathrm{~mol} \%)$, amide (0.25 mmol), [Me $\mathrm{MSiOTf}$ 
(10-12.5 mol\%) as additive and $n$-heptane $(2.0 \mathrm{~mL})$ as solvent. Afterwards, the reaction vial was capped with a septum equipped with a syringe and set in an alloy plate, which was then placed into a $300 \mathrm{~mL}$ autoclave. Once sealed, the autoclave was purged three times with 30 bar of hydrogen, then pressurized to 5-10 bar and placed into an aluminum block, which was preheated at $125-135{ }^{\circ} \mathrm{C}$. After $14 / 24 \mathrm{~h}$, the autoclave was cooled in an ice bath, and the remaining gas was carefully released. Finally, $n$-hexadecane $(20 \mathrm{mg})$ was added as an external standard and the reaction mixture was diluted with ethyl acetate and analyzed by GC-FID or it was purified directly by silica gel column chromatography to give the corresponding products as isolated yield.

\section{Conclusions}

The first cobalt-catalyzed protocol for the deoxygenative hydrogenation of amides to amines is described. The combination of $\left[\mathrm{Co}\left(\mathrm{NTf}_{2}\right)_{2}\right]$ or $\left[\mathrm{Co}\left(\mathrm{BF}_{4}\right)_{2} \cdot 6 \mathrm{H}_{2} \mathrm{O}\right]$ with $(p$ anisole)triphos ( $\mathrm{L} 3$ ) as a ligand, in the presence of [Me $\mathrm{MSiOTf}_{3}$ as a Lewis acid co-catalyst, performs the direct hydrogenation of a range of amides to amines under comparably mild conditions. Control experiments suggest that after an initial reduction of the amide to the corresponding hemiaminal intermediate, the amine formation is mainly attributed to a direct $\mathrm{C}-\mathrm{O}$ bond cleavage process. Nevertheless, some alternative minor pathways seem to be involved too. Interestingly, combining of the optimal ligand and $\left[\mathrm{Co}\left(\mathrm{BF}_{4}\right)_{2} \cdot 6 \mathrm{H}_{2} \mathrm{O}\right]$ led to the formation of the molecularly-defined pre-catalyst $\left[\mathrm{Co}(\mathrm{L} 3) \mathrm{F}_{2}\left(\mathrm{BF}_{4}\right)_{2}\right.$, which has never been isolated before. This specific homogeneous cobalt catalyst system showed enhanced activity and selectivity in comparison with related ruthenium system under identical conditions. In general, the direct hydrogenation of amides to amines continues to be one of the most challenging reactions for amine synthesis. The present works demonstrates that new and improved catalysts based on non-noble metals should be considered and studied more seriously for this "dream transformation".

\section{Conflicts of interest}

There are no conflicts to declare.

\section{Acknowledgements}

This work was supported by the state of MecklenburgVorpommern and the BMBF. We thank the analytical department (LIKAT) for their support, and the State of Mecklenburg-Western Pomerania and the Federal State of Germany (BMBF) for financial support. V.P. thanks the Ermenegildo Zegna Founder's Scholarship for financial support. J.R.C.-A. thanks the Spanish Minister of Science and Innovation for a Ramón y Cajal contract and Generalitat Valenciana for SEJI program funding. We also thank D. K. Leonard (LIKAT) for the assistance in manuscript preparation.

\section{Notes and references}

1. (a) V. Froidevaux, C. Negrell, S. Caillol, J.-P. Pascault and B. Boutevin, Chem. Rev. , 2016, 116, 14181-14224; (b) D. Dominissini, S. Moshitch-Moshkovitz, S. Schwartz, M. SalmonDivon, L. Ungar, S. Osenberg, K. Cesarkas, J. Jacob-Hirsch, N. Amariglio, M. Kupiec, R. Sorek and G. Rechavi, Nature, 2012, 485, 201-206; (c) S. D. Roughley and A. M. Jordan, J. Med. Chem., 2011, 54, 3451-3479; (d) A. Kleemann, J. Engel, B. Kutschner and D. Reichert, Pharmaceutical Substances: Syntheses, Patents, Applications, Thieme, Stuttgart, New York, 5th edn., 2009; (e) Modern Amination Methods, ed. A. Ricci, Wiley-VCH, Weinheim, 2008; (f) The Chemistry of Anilines, Part 1, Ed. Z. Rappoport, Wiley Interscience, 2007; (g) S. A. Lawrence, Amines: Synthesis, Properties and Applications, Cambridge University Press, Cambrigde, 2006; (h) J. M. Adams and S. Cory, Nature, 1975, 255, 28-33.

2. (a) R. V. Jagadeesh, K. Murugesan, A. S. Alshammari, H. Neumann, M.-M. Pohl, J. Radnik and M. Beller, Science, 2017, 358, 326-332; (b) S. Raoufmoghaddam, Org. Biomol. Chem., 2014, 12, 7179-7193; (c) V. N. Wakchaure, J. Zhou, S. Hoffmann and B. List, Angew. Chem. Int. Ed., 2010, 49, 4612-4614; (d) H. T. Clarke, H. B. Gillespie and S. Z. Weisshaus, J. Am. Chem. Soc., 1933, 55, 4571-4587.

3. (a) D. Formenti, F. Ferretti, F. K. Scharnagl and M. Beller, Chem. Rev. , 2019, 119, 2611-2680; (b) P. Serna and A. Corma, ACS Catal., 2015, 5, 7114-7121; (c) R. V. Jagadeesh, A.-E. Surkus, H. Junge, M.-M. Pohl, J. Radnik, J. Rabeah, H. Huan, V. Schuenemann, A. Brueckner and M. Beller, Science, 2013, 342, 1073-1076; (d) A. Corma and P. Serna, Science, 2006, 313, 332334.

4. D. B. Bagal and B. M. Bhanage, Adv. Synth. Catal., 2015, 357, 883900.

5. J. R. Cabrero-Antonino, R. Adam and M. Beller, Angew. Chem. Int Ed., 2019, 58, 12820-12838.

6. For general reviews about catalytic reduction of amides (mainly with molecular hydrogen), see: (a) Y. Zhou, R. Khan, B. Fan and L. Xu, Synthesis, 2019, 51, 2491-2505; (b) A. Y. Khalimon, K. A. Gudun and D. Hayrapetyan, Catalysts, 2019, 9, 490; (c) A. Chardon, E. Morisset, J. Rouden and J. Blanchet, Synthesis, 2018, 50, 984-997; (d) S. Werkmeister, K. Junge and M. Beller, Org. Process Res. Dev., 2014, 18, 289-302; (e) A. M. Smith and R. Whyman, Chem. Rev., 2014, 114, 5477-5510; (f) D. L. Dodds and D. J. Cole-Hamilton, in Sustainable Catalysis: Challenges and Practices for the Pharmaceutical and Fine Chemical Industries, eds. P. J. Dunn, K. K. M. Hii, M. J. Krische and M. T. Williams, John Wiley \& Sons, Inc., Hoboken, New Jersey, 2013, ch. 1, pp. 1-36; (g) P. A. Dub and T. Ikariya, ACS Catal., 2012, 2, 1718-1741; (h) M. Ito and T. Ikariya, Chem. Commun., 2007, 5134-5142.

7. (a) H. Noda, M. Furutachi, Y. Asada, M. Shibasaki and N. Kumagai, Nat. Chem., 2017, 9, 571-577; (b) A. Ojeda-Porras and D. GambaSánchez, J. Org. Chem., 2016, 81, 11548-11555; (c) I. Kreituss and J. W. Bode, Acc. Chem. Res., 2016, 49, 2807-2821; (d) R. M. deFigueiredo, J.-S. Suppo and J.-M. Campagne, Chem. Rev. , 2016, 116, 12029-12122; (e) P. Crochet and V. Cadierno, Top. Organomet. Chem., 2015, 48, 81-118.

8. (a) G. E. Arnott, in Comprehensive Organic Synthesis, eds. P. Knochel and G. A. Molander, Elsevier B.V., 2nd edn., 2014, vol. 8, pp. 368-409; (b) J. Magano and J. R. Dunetz, Org. Process Res. Dev., 2012, 16, 1156-1184; (c) G. W. Gribble, Chem. Soc. Rev., 1998, 27, 395-404. 
9. For a recent example about non-catalytic protocol using sodium hydride with zinc halides for the highly controlled reduction of amides to alcohols/amines or higher amines, see: (a) D. Y. Ong, Z. Yen, A. Yoshii, J. Revillo Imbernon, R. Takita and S. Chiba, Angew. Chem. Int. Ed., 2019, 58, 4992-4997; For recent noncatalytic examples about single-electron-transfer reductions of amides to alcohols/amines mediated by $\left[\mathrm{Sml}_{2} / \mathrm{amine} / \mathrm{H}_{2} \mathrm{O}\right]$, see: (b) S. R. Huq, S. Shi, R. Diao and M. Szostak, J. Org. Chem., 2017, 82, 6528-6540; (c) M. Szostak, M. Spain, A. J. Eberhart and D. J. Procter, J. Am. Chem. Soc., 2014, 136, 2268-2271; For a recent non-catalytic example about single-electron-transfer reduction amides to alcohols/amines or higher amines with sodium dispersions with different proton donors, see: (d) B. Zhang, H. Li, Y. Ding, Y. Yan and J. An, J. Org. Chem., 2018, 83, 6006-6014; For selected examples about non-catalytic reduction of amides to higher amines through electrophilic activation of the amide bond with $\left[\mathrm{Tf}_{2} \mathrm{O}\right]$ in the presence of different reducing agents, see: (e) P.-Q. Huang, Q.-W. Lang and Y.-R. Wang, J. Org. Chem., 2016, 81, 4235-4243; (f) G. Pelletier, W. S. Bechara and A. B. Charette, J. Am. Chem. Soc., 2010, 132, 12817-12819; (g) G. Barbe and A. B. Charette, J. Am. Chem. Soc., 2008, 130, 18-19; For an elegant example about non-catalytic selective reduction of amides to aldehydes mediated by Schwartz's reagent, see: (h) J. T. Spletstoser, J. M. White, A. R. Tunoori and G. I. Georg, J. Am. Chem. Soc., 2007, 129, 3408-3419.

10. For general reviews about catalytic reduction of amides with hydrosilanes or hydroboranes, see also references $6 a, 6 b, 6 c$ and: (a) A. Volkov, F. Tinnis, T. Slagbrand, P. Trillo and H. Adolfsson, Chem. Soc. Rev., 2016, 45, 6685-6697; (b) B. Li, J.-B. Sortais and C. Darcel, RSC Adv., 2016, 6, 57603-57625; (c) H. Nagashima, Synlett, 2015, 26, 866-890; (d) D. S. Merel, M. L. T. Do, S. Gaillard, P. Dupau and J.-L. Renaud, Coord. Chem. Rev., 2015, 288, 50-68; (e) D. Addis, S. Das, K. Junge and M. Beller, Angew. Chem. Int. Ed., 2011, 50, 6004-6011.

11. D. Cantillo, Eur. J. Inorg. Chem., 2011, 3008-3013.

12. L. Castoldi, W. Holzer, T. Langer and V. Pace, Chem. Commun., 2017, 53, 9498-9501.

13. (a) S. G. Koenig, D. K. Leahy and A. S. Wells, Org. Process Res. Dev., 2018, 22, 1344-1359; (b) D. J. C. Constable, P. J. Dunn, J. D. Hayler, G. R. Humphrey, J. L. Leazer, Jr., R. J. Linderman, K. Lorenz, J. Manley, B. A. Pearlman, A. Wells, A. Zaks and T. Y. Zhang, Green Chem., 2007, 9, 411-420.

14. For examples about heterogeneous catalyzed C-N amide hydrogenation, see: (a) I. Sorribes, S. C. S. Lemos, S. Martin, A. Mayoral, R. C. Lima and J. Andres, Catal. Sci. Technol., 2019, 9, 6965-6976; (b) Y. Xie, P. Hu, T. Bendikov and D. Milstein, Catal. Sci. Technol., 2018, 8, 2784-2788; (c) M. Tamura, S. Ishikawa, M. Betchaku, Y. Nakagawa and K. Tomishige, Chem. Commun., 2018, 54, 7503-7506.

15. For examples about heterogeneous catalyzed C-O amide hydrogenation, see: (a) R. Kadyrov, Adv. Synth. Catal., 2019, 361, 185-191; (b) R. Coeck, S. Berden and D. E. De Vos, Green Chem. 2019, 21, 5326-5335; (c) T. Chen, Z. Shi, G. Zhang, H. C. Chan, Y. Shu, Q. Gao and Y. Tang, ACS Appl. Mater. Interfaces, 2018, 10, 42475-42483; (d) T. Toyao, S. M. A. H. Siddiki, Y. Morita, T. Kamachi, A. S. Touchy, W. Onodera, K. Kon, S. Furukawa, H. Ariga, K. Asakura, K. Yoshizawa and K.-i. Shimizu, Chem. Eur. J., 2017, 23, 14848-14859; (e) T. Mitsudome, K. Miyagawa, Z. Maeno, T. Mizugaki, K. Jitsukawa, J. Yamasaki, Y. Kitagawa and K. Kaneda, Angew. Chem. Int. Ed., 2017, 56, 9381-9385; (f) K.-i. Shimizu, W. Onodera, A. S. Touchy, S. M. A. H. Siddiki, T. Toyao and K. Kon, ChemistrySelect, 2016, 1, 736-740; (g) S. Li, H. Chen, M. Wen and
J. Shen, J. Catal., 2016, 338, 1-11; (h) Y. Nakagawa, R. Tamura, M. Tamura and K. Tomishige, Sci. Technol. Adv. Mater., 2015, 16, 014901/014901-001491/014907; (i) M. Stein and B. Breit, Angew. Chem. Int. Ed., 2013, 52, 2231-2234; (j) J. Coetzee, H. G. Manyar, C. Hardacre and D. J. Cole-Hamilton, ChemCatChem, 2013, 5, 2843-2847; (k) R. Burch, C. Paun, X. M. Cao, P. Crawford, P. Goodrich, C. Hardacre, P. Hu, L. McLaughlin, J. Sa and J. M. Thompson, J. Catal., 2011, 283, 89-97; (I) G. Beamson, A. J. Papworth, C. Philipps, A. M. Smith and R. Whyman, J. Catal., 2011, 278, 228-238; (m) G. Beamson, A. J. Papworth, C. Philipps, A. M. Smith and R. Whyman, Adv. Synth. Catal., 2010, 352, 869883; (n) G. Beamson, A. J. Papworth, C. Philipps, A. M. Smith and R. Whyman, J. Catal., 2010, 269, 93-102; (o) C. Hirosawa, N. Wakasa and T. Fuchikami, Tetrahedron Lett., 1996, 37, 67496752; (p) H. S. Broadbent and W. J. Bartley, J. Org. Chem., 1963, 28, 2345-2347; (q) A. Guyer, A. Bieler and G. Gerliczy, Helv. Chim. Acta, 1955, 38, 1649-1654; (r) H. J. Schneider, H. Adkins and S. M. MeElvain, J. Am. Chem. Soc., 1952, 74, 4287-4290; (s) H. Adkins and B. Wojcik, J. Am. Chem. Soc., 1934, 56, 247-247.

16. For examples about homogeneous catalyzed C-N amide hydrogenation, see: (a) S. Kar, M. Rauch, A. Kumar, G. Leitus, Y. Ben-David and D. Milstein, ACS Catal., 2020, 10, 5511-5515; (b) T. Leischner, L. Artús Suarez, A. Spannenberg, K. Junge, A. Nova and M. Beller, Chem. Sci., 2019, 10, 10566-10576; (c) J. Chen, J. Wang and T. Tu, Chem. Asian J., 2018, 13, 2559-2565; (d) L. Artus Suarez, Z. Culakova, D. Balcells, W. H. Bernskoetter, O. Eisenstein, K. I. Goldberg, N. Hazari, M. Tilset and A. Nova, ACS Catal., 2018, 8, 8751-8762; (e) Z. Wang, Y. Li, Q.-b. Liu, G. A. Solan, Y. Ma and W.-H. Sun, ChemCatChem, 2017, 9, 4275-4281; (f) L. Shi, X. Tan, J. Long, X. Xiong, S. Yang, P. Xue, H. Lv and X. Zhang, Chem. Eur. J., 2017, 23, 546-548; (g) L. Rasu, J. M. John, E. Stephenson, R. Endean, S. Kalapugama, R. Clement and S. H. Bergens, J. Am. Chem. Soc., 2017, 139, 3065-3071; (h) V. Papa, J. R. CabreroAntonino, E. Alberico, A. Spanneberg, K. Junge, H. Junge and M. Beller, Chem. Sci., 2017, 8, 3576-3585; (i) T. Miura, M. Naruto, K. Toda, T. Shimomura and S. Saito, Sci. Rep., 2017, 7, 1-10; (j) U. Jayarathne, Y. Zhang, N. Hazari and W. H. Bernskoetter, Organometallics, 2017, 36, 409-416; (k) F. Schneck, M. Assmann, M. Balmer, K. Harms and R. Langer, Organometallics, 2016, 35, 1931-1943; (I) N. M. Rezayee, D. C. Samblanet and M. S. Sanford, ACS Catal., 2016, 6, 6377-6383; (m) P. Hu, Y. Ben-David and D. Milstein, Angew. Chem. Int. Ed., 2016, 55, 1061-1064; (n) J. A. Garg, S. Chakraborty, Y. Ben-David and D. Milstein, Chem. Commun., 2016, 52, 5285-5288; (o) J. R. Cabrero-Antonino, E. Alberico, H.-J. Drexler, W. Baumann, K. Junge, H. Junge and M. Beller, ACS Catal., 2016, 6, 47-54; (p) J. M. John, R. Loorthuraja, E. Antoniuk and S. H. Bergens, Catal. Sci. Technol., 2015, 5, 11811186; (q) P. Hu, E. Fogler, Y. Diskin-Posner, M. A. Iron and D. Milstein, Nat. Commun., 2015, 6, 6:6859 doi: 6810.1038/ncomms7859; (r) Y. Kita, T. Higuchi and K. Mashima, Chem. Commun. , 2014, 50, 11211-11213; (s) T. Miura, I. E. Held, S. Oishi, M. Naruto and S. Saito, Tetrahedron Lett., 2013, 54, 2674-2678; (t) R. Barrios-Francisco, E. Balaraman, Y. DiskinPosner, G. Leitus, L. J. W. Shimon and D. Milstein, Organometallics, 2013, 32, 2973-2982; (u) J. M. John and S. H. Bergens, Angew. Chem. Int. Ed., 2011, 50, 10377-10380; (v) M. Ito, T. Ootsuka, R. Watari, A. Shiibashi, A. Himizu and T. Ikariya, J. Am. Chem. Soc., 2011, 133, 4240-4242; (w) E. Balaraman, B. Gnanaprakasam, L. J. W. Shimon and D. Milstein, J. Am. Chem. Soc., 2010, 132, 16756-16758; (x) M. Ito, L. W. Koo, A. Himizu, C. Kobayashi, A. Sakaguchi and T. Ikariya, Angew. Chem. Int. Ed., 2009, 48, 1324-1327. 
17. (a) K. Junge, V. Papa and M. Beller, Chem. Eur. J., 2019, 25, 122 143; (b) A. Mukherjee and D. Milstein, ACS Catalysis, 2018, 8, 11435-11469; (c) W. Liu, B. Sahoo, K. Junge and M. Beller, Acc. Chem. Res., 2018, 51, 1858-1869; (d) G. A. Filonenko, R. van Putten, E. J. M. Hensen and E. A. Pidko, Chem. Soc. Rev., 2018, 47, 1459-1483.

18. (a) D. L. Dodds, J. Coetzee, J. Klankermayer, S. Brosinski, W. Leitner and D. J. Cole-Hamilton, Chem. Commun., 2012, 48, 12249-12262; (b) A. A. Núñez Magro, G. R. Eastham and D. J. Cole-Hamilton, Chem. Commun., 2007, 3154-3156.

19. (a) J. Coetzee, D. L. Dodds, J. Klankermayer, S. Brosinski, W. Leitner, A. M. Z. Slawin and D. J. Cole-Hamilton, Chem. Eur. J., 2013, 19, 11039-11050; (b) T. vom Stein, M. Meuresch, D. Limper, M. Schmitz, M. Hoelscher, J. Coetzee, D. J. ColeHamilton, J. Klankermayer and W. Leitner, J. Am. Chem. Soc. 2014, 136, 13217-13225.

20. (a) M. Meuresch, S. Westhues, W. Leitner and J. Klankermayer, Angew. Chem. Int. Ed., 2016, 55, 1392-1395; (b) S. Westhues, M. Meuresch and J. Klankermayer, Angew. Chem. Int. Ed., 2016, 55, 12841-12844.

21. J. R. Cabrero-Antonino, E. Alberico, K. Junge, H. Junge and M. Beller, Chem. Sci., 2016, 7, 3432-3442

22. M.-L. Yuan, J.-H. Xie and Q.-L. Zhou, ChemCatChem, 2016, 8, 3036-3040.

23. (a) S. Wesselbaum, V. Moha, M. Meuresch, S. Brosinski, K. M. Thenert, J. Kothe, T. v. Stein, U. Englert, M. Holscher, J. Klankermayer and W. Leitner, Chem. Sci., 2015, 6, 693-704; (b) F. M. A. Geilen, B. Engendahl, M. Hölscher, J. Klankermayer and W. Leitner, J. Am. Chem. Soc., 2011, 133, 14349-14358.

24. M.-L. Yuan, J.-H. Xie, S.-F. Zhu and Q.-L. Zhou, ACS Catal., 2016, 6, 3665-3669.

25. O. Ogata, H. Nara, K. Matsumura and Y. Kayaki, Org. Lett., 2019, 21, 9954-9959.

26. Y.-Q. Zou, S. Chakraborty, A. Nerush, D. Oren, Y. Diskin-Posner, Y. Ben-David and D. Milstein, ACS Catal., 2018, 8, 8014-8019.

27. For an elegant recent example of metal-free hydrogenation of amides to amines by using oxalyl chloride as activating agent, see: N. A. Sitte, M. Bursch, S. Grimme and J. Paradies, J. Am. Chem. Soc., 2019, 141, 159-162.

28. (a) R. M. Bullock, Science, 2013, 342, 1054; (b) S. Enthaler, K. Junge and M. Beller, Angew. Chem. Int. Ed., 2008, 47, 3317-3321.

29. (a) P. J. Chirik, Acc. Chem. Res., 2015, 48, 1687-1695; (b) J.-L. Renaud and S. Gaillard, Synthesis, 2016, 48, 3659-3683.

30. W. Ai, R. Zhong, X. Liu and Q. Liu, Chem. Rev., 2018, 119, 28762953.

31. (a) N. Gorgas and K. Kirchner, Acc. Chem. Res., 2018, 51, 15581569; (b) B. Maji and M. K. Barman, Synthesis, 2017, 49, 3377 3393; (c) M. Garbe, K. Junge and M. Beller, Eur. J. Org. Chem., 2017, 2017, 4344-4362; (d) D. A. Valyaev, G. Lavigne and N. Lugan, Coord. Chem. Rev., 2016, 308, 191-235.

32. T. J. Korstanje, J. Ivar van der Vlugt, C. J. Elsevier and B. de Bruin, Science, 2015, 350, 298.

33. J. R. Cabrero-Antonino, R. Adam, V. Papa, M. Holsten, K. Junge and M. Beller, Chem. Sci., 2017, 8, 5536-5546.

34. (a) J. Schneidewind, R. Adam, W. Baumann, R. Jackstell and M. Beller, Angew. Chem. Int. Ed., 2017, 56, 1890-1893; (b) F. K. Scharnagl, M. F. Hertrich, G. Neitzel, R. Jackstell and M. Beller, Adv. Synth. Catal., 2019, 361, 374-379.

35. B. G. Schieweck and J. Klankermayer, Angew. Chem. Int. Ed., 2017, 56, 10854-10857.

36. J. R. Cabrero-Antonino, R. Adam, K. Junge and M. Beller, Chem. Sci., 2017, 8, 6439-6450.
37. (a) B. Emayavaramban, P. Chakraborty and B. Sundararaju, ChemSusChem, 2019, 12, 3089-3093; (b) W. Liu, B. Sahoo, A. Spannenberg, K. Junge and M. Beller, Angew. Chem. Int. Ed., 2018, 57, 11673-11677.

38. (a) J. Becica and G. E. Dobereiner, Org. Biomol. Chem., 2019, 17, 2055-2069; (b) W. Zhao and J. Sun, Chem. Rev., 2018, 118, 1034910392; (c) J. R. Cabrero-Antonino, I. Sorribes, K. Junge and M. Beller, Angew. Chem. Int. Ed., 2016, 55, 387-391; (d) J. R. Cabrero-Antonino, R. Adam, K. Junge and M. Beller, Catal. Sci. Technol., 2016, 6, 7956-7966; (e) I. Sorribes, J. R. CabreroAntonino, C. Vicent, K. Junge and M. Beller, J. Am. Chem. Soc., 2015, 137, 13580-13587; (f) X. Cui, Y. Li, C. Topf, K. Junge and M. Beller, Angew. Chem. Int. Ed., 2015, 54, 10596-10599; (g) Y. Li, I. Sorribes, T. Yan, K. Junge and M. Beller, Angew. Chem. Int. Ed., 2013, 52, 12156-12160.

39. For selected examples about the positive effect of non-polar solvents in homogeneous cobalt-catalyzed hydrogenations, see reference $16 \mathrm{~h}$ and: Z. Shao, S. Fu, M. Wei, S. Zhou and Q. Liu, Angew. Chem. Int. Ed., 2016, 55, 14653-14657.

40. For a recent review about transition metal-catalyzed transformations involving phthalimides, see: Y.-C. Yuan, C. Bruneau and R. Gramage-Doria, Synthesis, 2018, 50, 4216-4228.

41. (a) M. A. Bhat, M. A. Al-Omar, M. A. Ansari, K. M. A. Zoheir, F. Imam, S. M. Attia, S. A. Bakheet, A. Nadeem, H. M. Korashy, A. Voronkov, V. Berishvili and S. F. Ahmad, J. Med. Chem., 2015, 58, 8850-8867; (b) H. Miyachi, A. Azuma, A. Ogasawara, E. Uchimura, N. Watanabe, Y. Kobayashi, F. Kato, M. Kato and Y. Hashimoto, J. Med. Chem., 1997, 40, 2858-2865; (c) R. A. Glennon, N. A. Naiman, M. E. Pierson, J. D. Smith, A. M. Ismaiel, M. Titeler and R. A. Lyon, J. Med. Chem., 1989, 32, 1921-1926.

42. For examples about selective homogeneously catalyzed reduction of phthalimides to isoindolinones by using hydrosilanes or hydrogen, see: (a) G. Ding, C. Li, Y. Shen, B. Lu, Z. Zhang and X. Xie, Adv. Synth. Catal., 2016, 358, 1241-1250; (b) A. Arévalo, S. Ovando-Segovia, M. Flores-Alamo and J. J. García, Organometallics, 2013, 32, 2939-2943; (c) S. Das, D. Addis, L. R. Knoepke, U. Bentrup, K. Junge, A. Brueckner and M. Beller, Angew. Chem. Int. Ed., 2011, 50, 9180-9184.

43. (a) A. F. Watson, J. Liu, K. Bennaceur, C. J. Drummond, J. A. Endicott, B. T. Golding, R. J. Griffin, K. Haggerty, X. Lu, J. M. McDonnell, D. R. Newell, M. E. M. Noble, C. H. Revill, C. Riedinger, Q. Xu, Y. Zhao, J. Lunec and I. R. Hardcastle, Bioorg. Med. Chem. Lett., 2011, 21, 5916-5919; (b) S. Ito, Y. Hirata, Y. Nagatomi, A. Satoh, G. Suzuki, T. Kimura, A. Satow, S. Maehara, H. Hikichi, M. Hata, H. Ohta and H. Kawamoto, Bioorg. Med. Chem. Lett., 2009, 19, 5310-5313; (c) R. Ben Othman, R. Affani, M.-J. Tranchant, S. Antoniotti, V. Dalla and E. Duñach, Angew. Chem. Int. Ed., 2010, 49, 776-780; (d) J. Royer, M. Bonin and L. Micouin, Chem. Rev., 2004, 104, 2311-2352. 